\title{
Efficacy and Safety of Pediatric Procedural Sedation Outside the Operating Room
}

\author{
Thitima Sirimontakan ${ }^{1}$, Ninuma Artprom ${ }^{2}$ and Nattachai Anantasit (iD 1, \\ ${ }^{1}$ Department of Pediatrics, Ramathibodi Hospital, Mahidol University, 10400, Bangkok, Thailand \\ ${ }^{2}$ Department of Nursing, Ramathibodi Hospital, Mahidol University, Bangkok, Thailand \\ "Corresponding author: Associate Professor, Department of Pediatrics, Ramathibodi Hospital, Mahidol University, 10400, Bangkok, Thailand. Tel: +66-22012949, Email: \\ nattachai032@hotmail.com
}

Received 2020 June 16; Revised 2020 July 25; Accepted 2020 August 05.

\begin{abstract}
Background: The volume of pediatric Procedural Sedation and Analgesia (PSA) outside the operating room has been increasing. This high clinical demand leads non-anesthesiologists, especially pediatric intensivists, pediatricians, and emergency physicians, to take a role in performing procedural sedation. Our department has established the PSA service by pediatric intensivists since 2015.

Objectives: We aimed to assess the efficacy and safety of PSA outside the operating room conducted by pediatric intensivists and identify risk factors for severe adverse events.

Methods: This was a retrospective descriptive study conducted from January 2015 to July 2019. Children aged less than 20 years who underwent procedural sedation were included. We collected demographic data, sedative and analgesic medications, American Society of Anesthesiologists (ASA) Physical Status Classification, indications for sedation, the success of procedural sedation, and any adverse events.

Results: Altogether, 395 patients with 561 procedural sedation cases were included. The median age was 55 months (range: 15 to 119 months), and 58.5\% (231/395) were male. The rate of successful procedures under PSA was 99.3\%. Serious Adverse Events (SAE) occurred in $2.7 \%$. Patients who received more than three sedative medications had higher SAE than patients who received fewer medications (adjusted for age, location of sedation, type of procedure, and ASA classification) (odds ratio: $8.043 ; 95 \%$ CI: 2.472 26.173, $\mathrm{P}=0.001)$.

Conclusions: Our data suggest that children who undergo procedural sedation outside the operating room conducted by pediatric intensivists are safe and effectively treated. Receiving more than three sedative medications is the independent risk factor associated with serious adverse events.
\end{abstract}

Keywords: Procedural Sedation and Analgesia, Non-Anesthesiologist, Pediatric Intensivist

\section{Background}

Invasive diagnostic and therapeutic procedures have increased over the past few decades. The provision of moderate sedation and adequate analgesia has been poorly managed $(1,2)$. The number of procedural sedation cases outside the operating room has risen due to the increase in these procedures with a limited number of anesthesiologists (3-5). The high demand for these services has led subspecialists such as pediatric intensivists, pediatricians, and emergency physicians to stepping into performing Procedural Sedation and Analgesia (PSA). A prior large cohort study showed no difference among subspecialties' serious adverse events for pediatric procedural sedation (6). With the advance in medicine and the complexity of diseases, the patients' requirements range from painless di- agnostic radiology to frightening, unpleasant procedures (7-9). Inadequate sedation may cause unsuccessful procedures and other detrimental effects on both family and patients. Therefore, the sedation providers should be trained in the administration of sedative drugs, implementation of physiologic monitoring, assessment of sedation levels, and management of adverse events (10-14).

Besides, PSA is well recognized in developed countries, although there are limited data in Thailand, especially among pediatric patients. Our center has established the PSA service for hospitalized patients since 2015. To our knowledge, this is the first pediatric PSA service in Thailand. The indications for consultation include children who have a risk or history of difficult sedation, require an urgent procedure, or are requested by a radio- 
interventionist. A pediatric resident sedates children without the risk of difficult sedation or simple cases (including normal healthy or mild systemic disease cases).

\section{Objectives}

The objective of this study was to determine the safety and outcome of PSA outside the operating room among hospitalized children.

\section{Methods}

This study was performed in a tertiary care, academic center. We retrospectively analyzed the chart review of children aged one month to 20 years who underwent PSA performed by intensivists from January 1, 2015, to July 31, 2019. The included patients were children who had a risk or history of difficult sedation, required urgent procedure, or were requested by a radio-interventionist. Intubated patients and children who had the risk of difficult airway management were excluded. This study was approved by the Institutional Review Board (IRB) of the authors' center.

Our pediatric sedation team comprised four intensivists and a trained sedation nurse. All the members of the pediatric sedation team needed to satisfy particular pediatric advanced life support certification. The resuscitation and monitoring equipment included bag valve masks, endotracheal tubes, laryngeal mask airways, resuscitation medications, isotonic crystalloids, cuffed blood pressure, and pulse oximetry without capnography. While a physician performed the drug administration, the nurse continuously monitored the vital signs and oxygen saturation. The depth of sedation was assessed by the patient's level of consciousness and responsiveness. All significant changes in terms of vital signs and complications were reported and documented by using the standardized sedation records. We collected the demographic data variables, type, and the dose of sedative and analgesic medications, past medical history, the American Society of Anesthesiologists (ASA) Physical Status Classification, indications for sedation, the success of procedural sedation, and adverse events. Mild adverse events (mild AE) were defined as patients who developed urticaria, nausea, hypertension, hypersecretion, or oxygen desaturation of less than $95 \%$ without bradycardia. Severe Adverse Events (SAE) were defined as one of the following events: Laryngospasm requiring bag-mask ventilation, bradycardia, cardiac arrest, significant desaturation (a value of oxygen desaturation of less than $95 \%$ with bradycardia which required positive pressure ventilation), and hypotension.

\subsection{Statistical Analyses}

Data were analyzed using SPSS version 17.0 (IBM corporation, Armonk, New York). Descriptive statistics were used to summarize the baseline characteristics of the study subjects. The chi-square test was used to compare the differences in mild and severe adverse events. Multiple logistic regressions were used to identify independent variables associated with an increase in the odds ratio of experiencing SAE. A P-value of less than 0.05 was considered statistically significant.

\section{Results}

A total of 641 sedations performed by the PSA team were examined from January 2015 to July 2019. Eighty sedations were excluded due to intubation and the risk of a difficult airway. Thus, 561 PSA procedures performed on 395 patients were included in this study. The median age of the patients was 55 months (range: 19 to 122 months), 58.5\% (231/395) were male, and 90.5\% (508/561) belonged to ASA class III and IV (Table 1). The most common indication of PSA was central venous line access $(49 \%, 275 / 561)$. The common sedative medications were fentanyl $(68.8 \%, 368 / 561)$, midazolam $(65.6 \%, 368 / 561)$, ketamine $(55.4 \%, 311 / 561)$, propofol $(46.7 \%, 262 / 561)$, chloral hydrate $(6.8 \%, 38 / 561)$, dexmedetomidine $(2.9 \%, 16 / 561)$, morphine $(0.2 \%, 1 / 561)$, and etomidate $(0.2 \%, 1 / 561)$. The success rate of the procedure under PSA was 99.3\%. The procedure could not be completed successfully in only four children. Three patients failed due to an unsuccessful procedure. One patient failed due to inadequate sedation with a higher dose of medications. The sedation failure occurred in a four-year-old girl who received dexmedetomidine loading infusion of $1 \mathrm{mcg} / \mathrm{kg}$ over $15 \mathrm{~min}$, followed by a maintenance infusion of $1 \mathrm{mcg} / \mathrm{kg} / \mathrm{h}$, propofol $4.8 \mathrm{mg} / \mathrm{kg}$, and ketamine $2 \mathrm{mg} / \mathrm{kg}$; however, she could not be adequately sedated for magnetic resonance imaging of the brain.

Overall adverse events occurred in 3.9\% (22/561), including urticaria, nausea, hypertension, hypersecretion, oxygen desaturation, hypotension, and laryngospasm. Besides, 15 children experienced serious adverse events, including one patient with laryngospasm with cardiac arrest, seven patients with significant desaturation requiring high flow nasal cannula or noninvasive positive pressure ventilation, and seven patients with hypotension (Figure 1). The patient with cardiac arrest was a 12-monthold boy with a history of persistent stridor, sedated with midazolam, fentanyl, ketamine, and propofol for a bronchoscopy. A bronchoscope was passed through the nose 


\begin{tabular}{|lc|}
\hline Table 1. Baseline Characteristics of Included Patients & \\
\hline Characteristics & Number (\%) \\
\hline Number of patients & 395 \\
\hline Number of sedations & 561 \\
\hline Gender: Male & $231(58.5)$ \\
\hline Age (months) & $55(19,122)$ \\
\hline ASA class & \\
\hline I & $12(2.1)$ \\
\hline II & $41(7.3)$ \\
\hline III & $506(90.2)$ \\
\hline IV & $2(0.4)$ \\
\hline Procedural area & \\
\hline Pediatrics ward & $323(57.6)$ \\
\hline Radiology department & $158(28.1)$ \\
\hline Intensive care unit & $66(11.7)$ \\
\hline Neonatal intensive care unit & $14(2.5)$ \\
\hline Successful procedure & $557(99.3)$ \\
\hline Duration of procedure (min) & $30(20,45)$ \\
\hline Adverse events & $22(3.9)$ \\
\hline Mild AE & $7(1.2)$ \\
\hline Serious AE & $15(2.7)$ \\
\hline Indications of procedural sedation & $275(49)$ \\
\hline Central venous access & $135(24.1)$ \\
\hline U/S guide intervention & $47(8.4)$ \\
\hline Bronchoscope & $104(18.5)$ \\
\hline Others & \\
\hline$A b r e s$ & \\
\hline
\end{tabular}

Abbreviations: AE, adverse events; Serious AE, serious adverse events

down into the lung. He experienced laryngospasm and desaturation and required intubation. He received $30 \mathrm{sec}-$ onds of cardiopulmonary resuscitation and was admitted to the PICU. He was extubated within one hour and discharged home safely in the next two days without any sequelae.

The painless procedure was significantly associated with serious adverse events $(P<0.001)$. The SAE varied significantly by the location of sedation $(\mathrm{P}<0.001)$. The SAE rate was higher in the Pediatric Intensive Care Unit (PICU) and Neonatal Intensive Care Unit (NICU). The number of sedative medications was associated with SAE $(\mathrm{P}=$ 0.001 ) (Table 2). The multiple logistic regression analysis, adjusted for clinical variables that were significantly associated with SAE (age, location of sedation, type of procedure, ASA classification, and the number of sedative medications), showed that only patients who received more than three sedative medications had higher SAE than patients who received fewer medications (odds ratio: 8.043; 95\% CI: 2.472 - 26.173, P = 0.001). There was no significant difference in weight-based dosing of fentanyl, midazolam, ketamine, and propofol between the two groups (Figure 2).

\section{Discussion}

This study demonstrates the PSA delivery by pediatric intensivists in an upper-middle-income country. To our knowledge, this is the first study in pediatric PSA in Thai children with high ASA classification. The success rate of pediatric PSA was nearly $100 \%$, with a low rate of complications. The overall AE incidence was 3.9\%, and the rate of SAE was only 2.7\%. There were no deaths in our study. Moreover, PSA performed by intensivists had the benefit of expanding sedation services and reducing healthcare costs. Our results are consistent with previous studies $(15,16)$ that described the efficacy of PSA by a well-trained sedation team and a high-quality system of sedation service. Importantly, our sedation team comprised four staff with limited resources available. A recent guideline from the American Academy of Pediatrics recommends using an end-tidal carbon dioxide monitor during pediatric PSA (5). However, a systematic review showed no difference in cardiorespiratory adverse events between standard monitoring with and without capnography for emergency department procedural sedation (17). Virtual monitoring devices such as capnography were not mandated in this study. The SAE was successfully treated because of early recognition and prompt intervention, which could be reflective of resuscitation skill and sedation assessment.

Some patients required many sedative medications and multiple doses due to chronic underlying medi$\mathrm{cal} /$ surgical conditions and anxiety to achieve the level of comfort. In addition, some children experienced medical procedures and went through the traumatic stress related to their age and environment (18). The choice of medication for PSA depended on not only intensivists to maintain hemodynamic stability but also their need based on the duration of the procedure and drug sensitization in the children. Serious adverse events occurred, although drugs were administrated as less than the maximum recommended dose. Several studies have reported that adverse events were correlated with the number of drugs used (19, 20). Our study reported that patients who received more than three drugs had SAE eight times higher than patients who received fewer than three sedative drugs.

Painful stimuli were considered to have a protective effect on maintaining respiratory activity during PSA (16). This study demonstrated that painful procedures decreased SAE. We found the SAE rate was high in intensive 


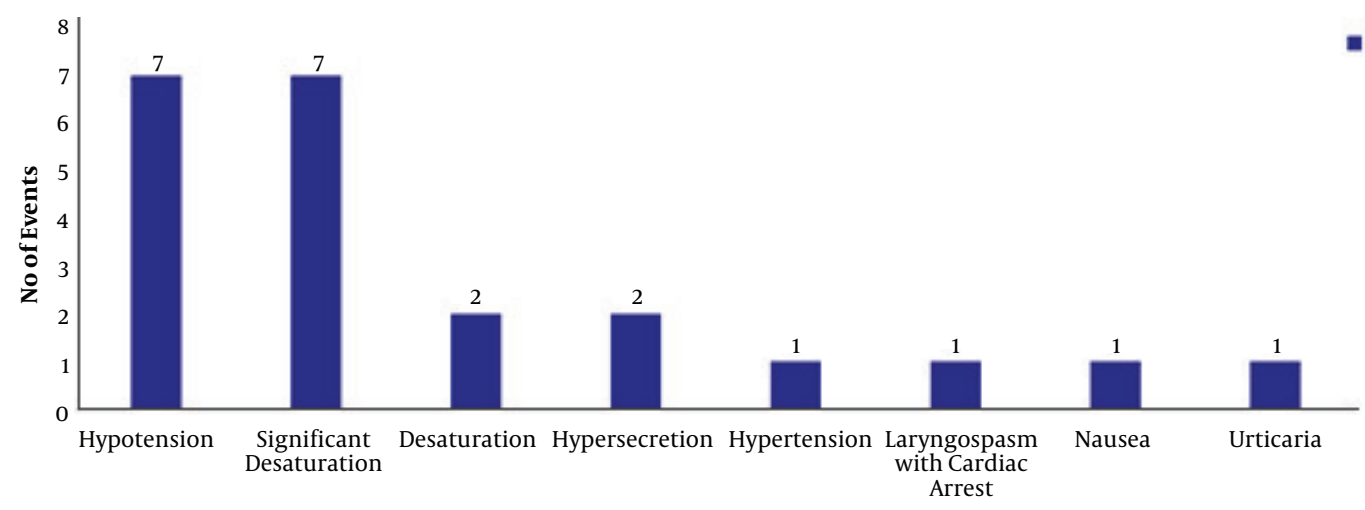

Figure 1. Type of adverse events

A

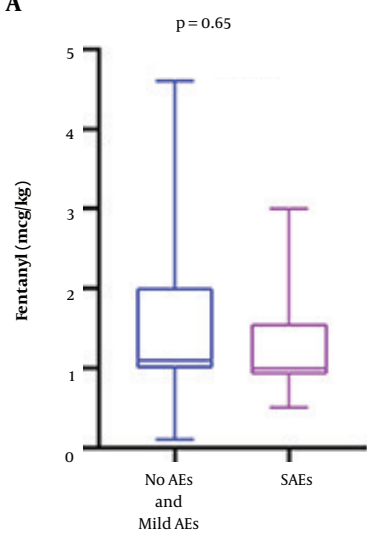

C

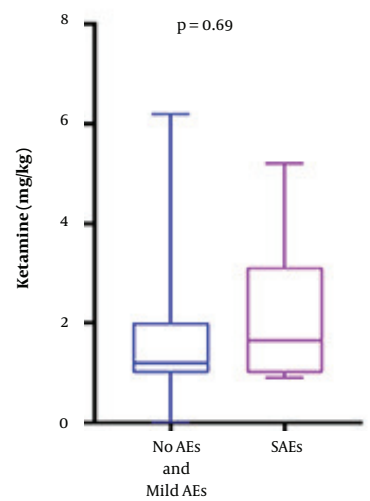

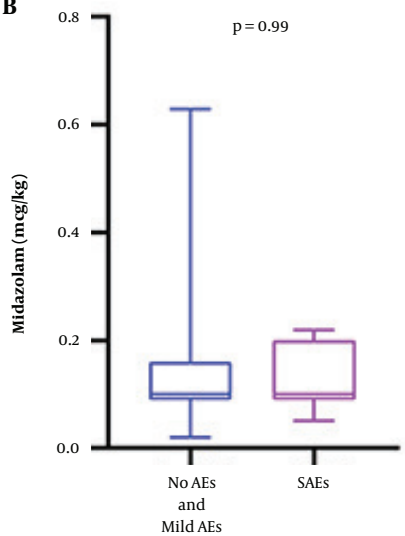

D

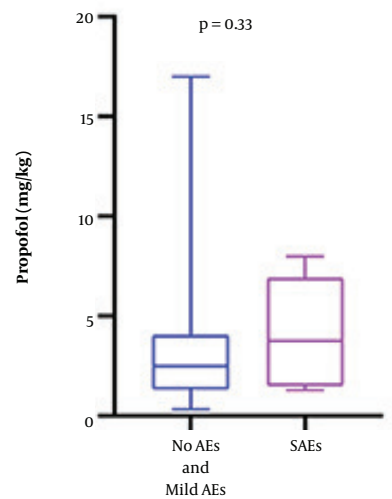

Figure 2. Comparison of the weight-based dosing of no AE and mild AE groups versus SAE group (A: fentanyl, B: midazolam, C: ketamine, D: propofol)

care units, including PICU and NICU. Most patients with adverse events in the ICU were patients who underwent flexible bronchoscopy. Our center routinely performed pe- diatric flexible bronchoscopy under sedation by the PSA team in the PICU. It can be explained by significant desaturation related to bronchoscopy that is performed in this 


\begin{tabular}{|c|c|c|c|}
\hline Variables & No $A E$ and mild $A E(N=546)$ & $\operatorname{SAEs}(\mathbf{N}=15)$ & P Value \\
\hline Age (months) & $57(19,112)$ & $32(12,160)$ & 0.713 \\
\hline Gender; male, No. (\%) & $306(56.0)$ & $8(53.3)$ & 0.835 \\
\hline \multicolumn{4}{|l|}{ ASA classification } \\
\hline ASA I-II & $50(9.1 \%)$ & $3(20.0 \%)$ & 0.161 \\
\hline ASA III-IV & $496(90.8 \%)$ & $12(80.0 \%)$ & 0.132 \\
\hline Sedation time (min) & $30(20,45)$ & $40(27.5,62.5)$ & 0.336 \\
\hline Comorbidities & & & 0.249 \\
\hline None & $8(1.5)$ & 0 & \\
\hline Hematology and oncology & $219(40)$ & $3(20)$ & \\
\hline Gastrointestinal and liver disease & $97(17.8)$ & $4(26.7)$ & \\
\hline Renal system & $64(11.7)$ & $2(13.3)$ & \\
\hline Respiratory system & $33(6.0)$ & $3(20.0)$ & \\
\hline Other & $125(22.9)$ & $3(20)$ & \\
\hline Painful procedure & $463(84.8)$ & $9(60)$ & $<0.001^{\mathrm{a}}$ \\
\hline Procedure & & & $0.002^{\mathrm{a}}$ \\
\hline Central venous access & $272(49.8)$ & $3(20.0)$ & \\
\hline $\mathrm{U} / \mathrm{S}$ guide intervention & $130(23.8)$ & $5(33.3)$ & \\
\hline Bronchoscope & $42(7.7)$ & $5(33.3)$ & \\
\hline Other & $102(18.7)$ & $2(13.3)$ & \\
\hline No. of sedative medication(s) received & & & $0.001^{\mathrm{a}}$ \\
\hline 1 & $56(10.3)$ & $1(6.7)$ & \\
\hline 2 & $232(42.5)$ & $4(26.7)$ & \\
\hline 3 & $218(39.9)$ & $4(26.7)$ & \\
\hline 4 & $40(7.3)$ & $6(40.0)$ & \\
\hline Location & & & $<0.001^{\mathrm{a}}$ \\
\hline PICU and NICU & $69(12.6)$ & $7(46.7)$ & \\
\hline Radiology unit & $153(28.0)$ & $5(33.3)$ & \\
\hline General pediatrics ward & $324(59.3)$ & $3(20.0)$ & \\
\hline
\end{tabular}

Abbreviations: PICU, pediatric intensive care unit; NICU, neonatal intensive care unit ${ }^{a}$ Significant at the level of 0.05 .

location. This is in contrast to a previous study, which reported a higher incidence of $\mathrm{AE}$ in pediatric dental offices (16).

Patients with ASA class I and II are considered good candidates for PSA $(4,5,7)$. Grunwell et al. (16) reported $72 \%$ of the population were ASA class I-II, and showed increasing adverse events among the patients with ASA class III-IV. Furthermore, for patients who had ASA class III-IV, Mallampati class III, or conditions increasing the risk of airway compromise, an anesthesiologist must be present (21). There was a prior study of performing PSA by nonanesthesiologists in adult patients who underwent gastro- endoscopy (22). The study showed no increase in adverse events in patients who had ASA class III. Another study showed no SAE in 29 out of 84 children who had ASA class III-IV and underwent computed tomography under anesthesiologists' supervision (23). This study showed that PSA could be safely performed without an anesthesiologist on patients with ASA classification of more than 3. In addition, $90 \%$ of the patients in this study had ASA class III-IV. It could be expressed that adverse events could not stratify the risk by ASA classification. 


\subsection{Study Limitations}

This study has limitations. First, it was a retrospective study in a single-center with a relatively small sample size. Second, the study did not have an actual protocol for PSA because it included patients with a variety of disorders.

\subsection{Conclusion}

If a hospital experiences an increasing demand for children undergoing PSA, pediatric intensivists may need to take a role in performing sedation service. Our data suggest that children who undergo procedural sedation outside the operating room conducted by pediatric intensivists are safe and effectively treated. The overall incidence of severe adverse events was low. Receiving four or more sedative medications is an independent risk factor associated with serious adverse events.

\section{Acknowledgments}

The authors express their gratitude to all colleagues in the Division of Pediatric Critical Care, Department of Pediatrics, Ramathibodi Hospital, Mahidol University. We would like to thank Mr. Stephen Pinder for critical review, and grammar correction. Furthermore, our special thanks go to all patients and parents in this study.

\section{Footnotes}

Authors' Contribution: TS and NA were the primary contributors to the origination of ideas and study protocol. All authors collected the data. TS and NA analyzed the data and drafted the manuscript. All authors read and approved the final manuscript.

Conflict of Interests: The author(s) declared no potential conflicts of interest concerning the research, authorship, and/or publication of this article.

Ethical Approval: The local Ethics Committee of Ramathibodi Hospital, Mahidol University, Thailand, approved all the procedures in this study (MURA2019/996).

Funding/Support: The author(s) received financial support for the research from Ramathibodi Research Funding.

\section{References}

1. Stevens BJ, Abbott LK, Yamada J, Harrison D, Stinson J, Taddio A, et al. Epidemiology and management of painful procedures in children in Canadian hospitals. CMAJ. 2011;183(7):E403-10. doi: 10.1503/cmaj.101341. [PubMed: 21464171]. [PubMed Central: PMC3080557].
2. Friedrichsdorf SJ, Postier A, Eull D, Weidner C, Foster L, Gilbert M, et al. Pain Outcomes in a US Children's Hospital: A Prospective CrossSectional Survey. Hosp Pediatr. 2015;5(1):18-26. doi:10.1542/hpeds.20140084. [PubMed: 25554755].

3. Metzner J, Domino KB. Risks of anesthesia or sedation outside the operating room: the role of the anesthesia care provider. Curr Opin Anaesthesiol. 2010;23(4):523-31. doi: 10.1097/ACO.0b013e32833b7d7c. [PubMed: 20531171].

4. Gozal D, Drenger B, Levin PD, Kadari A, Gozal Y. A pediatric sedation/anesthesia program with dedicated care by anesthesiologists and nurses for procedures outside the operating room. $J$ Pediatr. 2004;145(1):47-52. doi: 10.1016/j.jpeds.2004.01.044. [PubMed: 15238906].

5. Cote CJ, Wilson S, American Academy Of P, American Academy Of Pediatric D. Guidelines for Monitoring and Management of Pediatric Patients Before, During, and After Sedation for Diagnostic and Therapeutic Procedures. Pediatrics. 2019;143(6). doi: 10.1542/peds.20191000. [PubMed: 31138666].

6. Couloures KG, Beach M, Cravero JP, Monroe KK, Hertzog JH. Impact of provider specialty on pediatric procedural sedation complication rates. Pediatrics.2011;127(5):e1154-60.doi:10.1542/peds.2010-2960. [PubMed: 21518718].

7. Krauss B, Green SM. Procedural sedation and analgesia in children. Lancet. 2006;367(9512):766-80. doi: 10.1016/S0140-6736(06)68230-5. [PubMed: 16517277].

8. Youn AM, Ko YK, Kim YH. Anesthesia and sedation outside of the operating room. Korean J Anesthesiol. 2015;68(4):323-31. doi: 10.4097/kjae.2015.68.4.323. [PubMed: 26257843]. [PubMed Central: PMC4524929].

9. Campbell K, Torres L, Stayer S. Anesthesia and sedation outside the operating room. Anesthesiol Clin. 2014;32(1):25-43. doi: 10.1016/j.anclin.2013.10.010. [PubMed: 24491648].

10. Eichhorn V, Henzler D, Murphy MF. Standardizing care and monitoring for anesthesia or procedural sedation delivered outside the operating room. Curr Opin Anaesthesiol. 2010;23(4):494-9. doi: 10.1097|ACO.ob013e32833b9c9f. [PubMed: 20585246].

11. Cravero JP. Risk and safety of pediatric sedation/anesthesia for procedures outside the operating room. Curr Opin Anaesthesiol. 2009;22(4):509-13. doi: 10.1097/ACO.0b013e32832dba6e. [PubMed 19512915].

12. Melloni C. Anesthesia and sedation outside the operating room: how to prevent risk and maintain good quality. Curr Opin Anaesthesiol. 2007;20(6):513-9. doi: 10.1097/ACO.0b013e3282f06ba6. [PubMed: 17989542].

13. Cravero JP, Blike GT, Beach M, Gallagher SM, Hertzog JH, Havidich JE, et al. Incidence and nature of adverse events during pediatric sedation/anesthesia for procedures outside the operating room: report from the Pediatric Sedation Research Consortium. Pediatrics. 2006;118(3):1087-96. doi: 10.1542/peds.2006-0313. [PubMed: 16951002]

14. Pino RM. The nature of anesthesia and procedural sedation outside of the operating room. Curr Opin Anaesthesiol. 2007;20(4):347-51. doi 10.1097/ACO.ob013e32827035c7. [PubMed: 17620844].

15. Misra S, Mahajan PV, Chen X, Kannikeswaran N. Safety of procedural sedation and analgesia in children less than 2 years of age in a pediatric emergency department. Int J Emerg Med. 2008;1(3):173-7. doi:10.1007/s12245-008-0047-x. [PubMed: 19384511]. [PubMed Central: PMC2657272].

16. Grunwell JR, Travers C, McCracken CE, Scherrer PD, Stormorken AG, Chumpitazi CE, et al. Procedural Sedation Outside of the Operating Room Using Ketamine in 22,645 Children: A Report From the Pediatric Sedation Research Consortium. Pediatr Crit Care Med. 2016;17(12):1109-16. doi: 10.1097/PCC.0000000000000920. [PubMed 27505716]. [PubMed Central: PMC5138082]. 
17. Wall BF, Magee K, Campbell SG, Zed PJ. Capnography versus standard monitoring for emergency department procedural sedation and analgesia. Cochrane Database Syst Rev. 2017;3. CD010698. doi: 10.1002/14651858.CD010698.pub2. [PubMed: 28334427]. [PubMed Central: PMC6353146].

18. Pinto Filho WA, Silveira LHJ, Vale ML, Fernandes CR, Gomes JA Gabapentin in Improvement of Procedural Sedation and Analgesia in Oncologic Pediatric Patients: A Clinical Trial. Anesth Pain Med. 2019;9(5). e91197. doi: 10.5812/aapm.91197. [PubMed: 31903327]. [PubMed Central: PMC6935294].

19. Kamat PP, McCracken CE, Gillespie SE, Fortenberry JD, Stockwell JA, Cravero JP, et al. Pediatric critical care physician-administered procedural sedation using propofol: a report from the Pediatric Sedation Research Consortium Database. Pediatr Crit Care Med. 2015;16(1):11-20. doi: 10.1097/PCC.0000000000000273. [PubMed: 25340297].

20. Cote CJ, Notterman DA, Karl HW, Weinberg JA, McCloskey C. Adverse sedation events in pediatrics: a critical incident analysis of contributing factors. Pediatrics. 2000;105(4 Pt 1):805-14. doi: 10.1542/peds.105.4.805. [PubMed: 10742324].

21. Dumonceau JM, Riphaus A, Schreiber F, Vilmann P, Beilenhoff U, Aparicio JR, et al. Non-anesthesiologist administration of propofol for gastrointestinal endoscopy: European Society of Gastrointestinal Endoscopy, European Society of Gastroenterology and Endoscopy Nurses and Associates Guideline-Updated June 2015. Endoscopy. 2015;47(12):1175-89. doi: 10.1055/s-0034-1393414. [PubMed: 26561915].

22. Patel J, Fang J, Taylor LJ, Adler DG, Gawron AJ. Safety and efficacy of non-anesthesiologist administration of propofol sedation during esophagogastroduodenoscopy in the intensive care unit. Endosc Int Open. 2019;7(4):E625-9. doi: 10.1055/a-0829-6284. [PubMed:30993168]. [PubMed Central: PMC6461546].

23. Oh TK, Park B, Lee DE, Eom W, Kang S. Factors affecting propofol dosage for sedation in pediatric oncology. Pediatr Int. 2018;60(6):5359. doi: 10.1111/ped.13562. [PubMed: 29570916]. 